\title{
stanallia
}

DOI: 10.1002/smll.((please add manuscript number))

\section{Advanced Subcompartmentalized Microreactors: Polymer Hydrogel Carriers Encapsulating Polymer Capsules and Liposomes**}

Leticia Hosta-Rigau, Olga Shimoni, Brigitte Städler, and Frank Caruso*

[*] Prof. F. Caruso, O. Shimoni

Department of Chemical and Biomolecular Engineering, The University of Melbourne, Parkville, Victoria 3010, Australia

E-mail: fcaruso@unimelb.edu.au

Dr. L. Hosta-Rigau, Dr. B. Städler

Present address: Interdisciplinary Nanoscience Center, Aarhus University, Aarhus 8000, Denmark

Supporting Information is available on the WWW under http://www.small-journal.com or from the author.

Keywords: Capsosomes, compartmentalization, enzymatic reaction, microreactors, polymer hydrogel capsules

The design of compartmentalized carriers for advanced drug delivery systems or artificial cells and organelles is of interest for biomedical applications. Herein, we present a polymer carrier microreactor that contains two different classes of subcompartments: multilayered polymer capsules and liposomes. We encapsulate $50 \mathrm{~nm}$-diameter liposomes and $300 \mathrm{~nm}$-diameter polymer capsules into a larger polymer carrier capsule, demonstrating control over the spatial positioning of the subcompartments, which are either "membrane-associated" or "free-floating" in the aqueous interior. Selective and spatially dependent degradation of the $300 \mathrm{~nm}$-diameter subcompartments (without destroying the structural integrity of the enzyme-loaded liposomes) is also shown by performing an encapsulated enzymatic reaction using the liposomal subcompartments. These findings cover several important aspects toward the development of engineered compartmentalized carrier vessels for the creation of artificial cell mimics or advanced therapeutic delivery systems. 


\section{stmall}

\section{Introduction}

Biomimicry, or the creation of artificial mimics, holds great potential since synthetic biological systems will allow for a better understanding of biology by dissociating parameters that are closely correlated in nature. ${ }^{[1]}$ Since cells are the integral components of biological systems, the creation of artificial cells remains the focus of biomimicry and, thus, the past years have seen a steady stream of reports of model systems aimed at the creation of artificial cell mimics. ${ }^{[1 \mathrm{a}, 2]}$ Two completely different approaches have arisen for the creation of artificial cells: i) systems that encapsulate cell components, i.e., using cells as building blocks (top-down approach) ${ }^{[3]}$ and ii) synthetic microreactors that combine minimal components to create simple, typically one, cell function (bottom-up approach). ${ }^{[2-4]}$

Although the synthetic microreactors created from a bottom-up approach are still extremely simplified versions of cell architectures, the advantages of creating such biomimetic nanocontainers are two-fold: from the fundamental point of view, the creation of deliberately simplified systems is a powerful strategy to unravel the complexity of living cells while, at the same time, those biomimetic containers are an efficient tool with applications in the field of drug delivery, encapsulated catalysis, and diagnostics. ${ }^{[5]}$

However, the first step to mimic the structure of a cell is already very challenging: dividing the space in a controllable manner into subunits is a feature of eukaryotic cells, which, given their spatially confined environments (i.e., organelles), are able to separate in time and space the functional processes needed for its survival. Thus, for the successful creation of cell mimics, compartmentalization is essential.

However, despite the need of a broad range of synthetic microreactors created from a bottom-up approach, few examples of successful subcompartmentalized carriers have been reported to date. 


\section{smallion}

Those architectures are typically made of a single component and include vesosomes (liposomes within a carrier liposome), ${ }^{[6]}$ two compartment micellar assemblies ${ }^{[7]}$ polymer caspsule(s) within a polymer capsule,$^{[8]}$ and polymersomes within a polymersome. ${ }^{[1 b, 9]}$ Dual-composition systems in which the carrier container and the subcompartments are of different nature are even more scarce and include polymer hydrogel capsules containing cubosomes ${ }^{[10]}$ or polymersomes, ${ }^{[1]}$ cellosomes (yeast cells associated with a polymer membrane), ${ }^{[12]} \mathrm{CaCO}_{3}$ particles with subcompartments composed of biomolecules, ${ }^{[13]}$ and our recently introduced capsosomes, ${ }^{[14]}$ which comprise thousands of intact liposomes embedded into a polymer carrier capsule and are, to date, the most thoroughly studied subcompartmentalized system..$^{[5]}$

Capsosomes, as dual-composition systems, exploit the advantages of the different nature of the carrier vessel and the subcompartments. While the polymer carrier capsule provides the structural scaffold with controllable permeability, the liposomes, which partition the capsule's interior into subcompartments, are well suited to encapsulate small and/or fragile cargo due to their impermeable nature. We have broadly characterized the fabrication of capsosomes ${ }^{[15]}$ and have developed a unique approach to non-covalently anchor liposomes to polymer layers using cholesterol. ${ }^{[14,16]} \mathrm{We}$ have also shown control over the position of the liposomal subcompartments; that is, capsosomes containing "membrane-associated" or "free-floating" (filling the cavity of the capsules) subcompartments. ${ }^{[17]}$ Further, we have demonstrated the functionality of capsosomes by performing two different triggered enzymatic assays ${ }^{[14,17]}$ and a two-step enzymatic catalytic reaction. ${ }^{[18]}$ The absence of inherent cytotoxicity of capsosomes (by performing a cell viability assay) ${ }^{[19]}$ makes capsosomes promising candidates for biomedical applications.

We have also reported $3 \mu \mathrm{m}$-diameter polymer hydrogel capsules containing $300 \mathrm{~nm}$-diameter subcompartments, namely subcompartmentalized hydrogel capsules, in which both the carrier capsule and the subcompartments are semipermeable, and we demonstrated the selective 


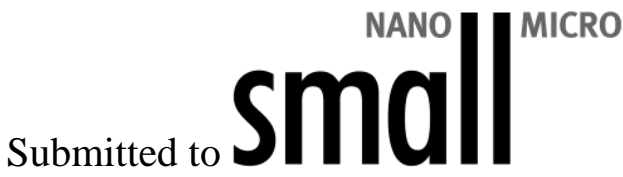

degradation of the subcompartments and the carrier capsules to different chemical stimuli. ${ }^{[8 c]}$ In addition, we pioneered continuous reactions performed in semipermeable polymer hydrogel capsules that mimic some of the activities performed in different cell organelles, such as the enzymatic degradation of DNA ${ }^{[20]}$ or RNA synthesis. ${ }^{[21]}$

However, all carriers containing subcompartments reported to date, including capsosomes and subcompartmentalized hydrogel capsules, have a common feature: all of the subcompartments are of the same type. On one hand, for the design of successful mimics of cells, several types of compartments should be encapsulated since, in biological cells, compartmentalization is not limited to lipid containers; other small scale containers such as chaperones, which exert functions such as assisting in protein folding, ferritins, involved in iron metabolism, or proteasomes for protein degradation, which are not formed by a lipid bilayer, are also cell compartments. ${ }^{[22]}$ On the other hand, when making use of advanced compartmentalized carriers for biomedical applications such as drug delivery, given the tremendous complexities of pharmacokinetics and pharmacodynamics of potential drugs and the immense variety of human diseases, it is envisioned that carriers containing different types of subcompartments will be an optimal form of drug delivery. Using multiple and different compartments in which their chemistry and physics can be modified in different ways due to their intrinsic different properties, will offer a new broad range of multiple and diverse possibilities that are not possible when using a single type of subcompartment.

In this work, we give a first insight into the creation of a synthetic microreactor containing two different types of subcompartments: liposomes and polymer hydrogel capsules, and demonstrate the specific functionality of the different subunits. We envision that by incorporating two different types of subcompartments into a polymer carrier vessel, complementary cell functions could potentially be performed in parallel within the same container, bringing us a step closer to the creation of advanced cell mimics that are able to perform several cell functions at the same time. 


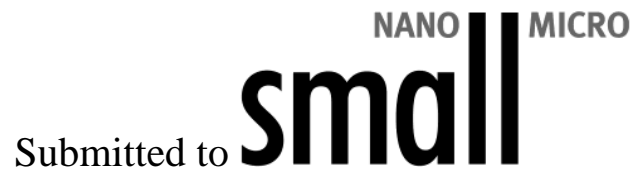

While liposomes will equip the synthetic microreactor with all the features already described and reported for capsosomes, the polymeric subcompartments will endow them with the additional functionalities of a semipermeable capsule, since liposomes have some limitations such as a low loading capacity or a lack of permeability toward small molecules. As an example, the incorporation of polymeric subcompartments containing a semipermeable membrane could allow the synthetic microreactor to perform continuous reactions in which the intake of reagents and release of products is constant, while liposomes will perform a different task, by initiating the enzymatic reaction in response to a trigger.

In this study, which is aimed at the creation of an advanced synthetic microreactor, we: i) encapsulate $300 \mathrm{~nm}$-diameter polymeric hydrogel capsules $\left(\mathrm{HC}_{300}\right)$ and liposomes separated by different polymer layers within a (bio)degradable polymer membrane (Scheme 1); ii) study the kinetics of the liposomal adsorption onto $\mathrm{HC}_{300}$-coated silica templates; iii) make use of the properties of poly $\left(N\right.$-vinyl pyrrolidone-block-(cholesteryl acrylate) $\left(\mathrm{PVP}_{\mathrm{c}}\right)$ as a polymer separation layer to assemble a carrier vehicle containing "free-floating" liposomal subcompartments and "membrane-associated" $\mathrm{HC}_{300}$; iv) demonstrate the selective degradation of the polymeric subcompartments under reductive conditions (in contrast to the liposomal subcompartments, which remain intact); v) show that the degradability of the $\mathrm{HC}_{300}$ depends on the spatial positioning of the liposomes; and vi) confirm the functionality of these compartmentalized carriers through an encapsulated enzymatic reaction.

\section{Results and Discussion}

\subsection{Microreactor Assembly}

The assembly of both $\mathrm{HC}_{300}$ and the carrier vessels is based on the layer-by-layer (LbL) technique by the consecutive alternate adsorption of poly( $N$-vinyl pyrrolidone) (PVP) and thiolated 


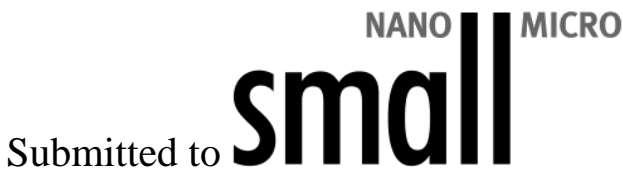

poly(methacrylic acid) (PMAsH) onto sacrificial particle templates. The PMAsH thiol groups in the multilayers were cross-linked and upon core removal the capsules were washed in HEPES buffer (10 mM HEPES (4-(2-hydroxyethyl)-1-piperazineethanesulfonic acid), $150 \mathrm{mM} \mathrm{NaCl}$, $\mathrm{pH}$ 7.4) to yield negatively charged, single-component PMA capsules (Figure 1a) ${ }^{[8 c, 23]}$.

We assembled a heterogeneous microreactor by first adsorbing $\mathrm{HC}_{300}$ onto amine-modified, positively charged, $3 \mu \mathrm{m}$-diameter silica template $\left(\mathrm{SiO}_{2}{ }^{+}\right)$particles via electrostatic interactions. ${ }^{[8 c]}$ Next, two different polymer separation layers (poly(L-lysine) (PLL) and/or poly(methacrylic acid)co-(cholesteryl methacrylate) $\left.\left(\mathrm{PMA}_{\mathrm{c}}\right)\right)$ in HEPES buffer were deposited prior to adsorption of different types of nitrobenzoxadiazole (NBD)-labeled liposomes (i.e., zwitterionic unsaturated liposomes $\left(\mathrm{L}^{\mathrm{u}, \mathrm{ZW}_{\mathrm{NBD}}}\right)$; negatively charged unsaturated liposomes ( $\left.\mathrm{L}^{\mathrm{u},-} \mathrm{NBD}\right)$; zwitterionic saturated liposomes $\left(\mathrm{L}^{\mathrm{s}, \mathrm{ZW}} \mathrm{NBD}\right)$; negatively charged saturated liposomes $\left.\left(\mathrm{L}^{\mathrm{s},{ }^{-} \mathrm{NBD}}\right)\right)$ to identify which polymer or combination of polymers allows the maximum adsorption of each type of liposomes onto the $\mathrm{HC}_{300}$-coated $\mathrm{SiO}_{2}{ }^{+}$particles $\left(\mathrm{SiO}_{2}{ }^{+}-\mathrm{HC}_{300}\right)$. We chose PLL and the combination PLL/PMA since both polymers have been previously demonstrated to be effective precursor layers for liposome

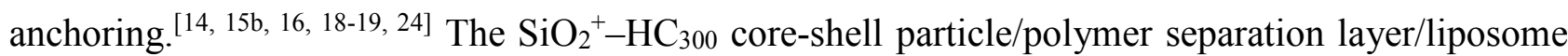
assembly was then capped with PMAc in HEPES buffer and the polymer carrier capsule was created by the sequential deposition of five bilayers of PVP and PMA $\mathrm{SH}_{\mathrm{sH}}$ in NaOAc buffer $(20 \mathrm{mM} \mathrm{NaOAc}$ (sodium acetate), $\mathrm{pH} 4.0) \cdot{ }^{[23]}$ The thiols in the polymer multilayer film of the core-shell particles were then cross-linked followed by dissolution of the silica particle templates in $5 \mathrm{M}$ hydrofluoric acid (HF). The fluorescence intensity of the core-shell particles due to the fluorescent liposomes was monitored by flow cytometry. The fluorescence reading measured after adsorption of the liposomes was set at $100 \%$ and compared to the fluorescence intensity of the core-shell particles after cross-linking and after core dissolution at both assembly (NaOAc buffer) and physiological 


\section{smallio}

(HEPES buffer) conditions. Figure 1b shows the measured decrease in fluorescence intensity for eight different combinations of polymer separation layers and liposomes.

The separation layer adsorbed between the $\mathrm{HC}_{300}$ and the unsaturated liposomes has a significant influence on the retention of both zwitterionic $\left(\mathrm{L}^{\mathrm{u}, \mathrm{Zw}}{ }_{\mathrm{NBD}}\right)$ and negatively charged $\left(\mathrm{L}^{\mathrm{u},-} \mathrm{NBD}\right)$ liposomes. For $\mathrm{L}^{\mathrm{u}, \mathrm{Zw}} \mathrm{NBD}$ the combination of PLL/PMA as separation layer led to a reduction of $\sim 35 \%$ in fluorescence intensity in contrast to a decrease of only $\sim 6 \%$ when PLL was used as separation layer, when comparing the decrease in fluorescence intensity after the initial liposome deposition step (Figure 1bi, dark gray bars) and after the assembly of the core-shell particles (Figure 1bi, light gray bars). This finding can be explained by the fact that when employing the combination of PLL/PMA $A_{c}$ as separation layer, the $\mathrm{L}^{\mathrm{u}, \mathrm{Zw}} \mathrm{NBD}$ are sandwiched between two layers of $\mathrm{PMA}_{c}$ assembled in HEPES buffer, thus being negatively charged and repelling each other. The electrostatic repulsion between the capping and separation polymer layers will prevent efficient embedding of the cholesterol moieties into the liposomes, thus promoting the displacement of the liposomes. In contrast, when PLL is employed as separation layer, the $\mathrm{L}^{\mathrm{u}, \mathrm{zw}}{ }_{\mathrm{NBD}}$ are sandwiched between a positively charged PLL separation layer and a negatively charged $\mathrm{PMA}_{c}$ capping layer, making the electrostatic interactions favorable and, in turn, promoting stable anchoring of the liposomes due to the cholesterol moieties of the capping layer. However, as shown in Figure 1bii, the liposomal trapping efficiency appears to be dependent on the separation layer in an opposite manner when encapsulating $\mathrm{L}^{\mathrm{u},-}{ }_{\mathrm{NBD}}$. When using the combination of PLL/PMA $A_{c}$ to separate $\mathrm{L}^{\mathrm{u},-}{ }_{\mathrm{NBD}}$ from the $\mathrm{HC}_{300}$, a fluorescence decrease of only $\sim 20 \%$ was observed (Figure 1bii, light gray bars) compared to a decrease of $\sim 40 \%$ in fluorescence when PLL was used as a separation layer (Figure 1bii, light gray bars). A possible explanation for these observations is that when employing PLL as a separation layer (in this case the liposomes are negatively charged), upon the addition of the negatively charged $\mathrm{PMA}_{\mathrm{c}}$ capping layer, a strong electrostatic repulsion between the $\mathrm{PMA}_{\mathrm{c}}$ capping 


\section{stranestismall}

layer and the negatively charged liposomes will occur, and given that the liposomes are bound to PLL by electrostatic interactions, the PMA $\mathrm{A}_{\mathrm{c}}$ capping layer may strongly interact with the underlying PLL and displace loosely bound liposomes. However, when the combination of PLL/PMA as a separation layer, stable anchoring of the negatively charged liposomes will be provided by the cholesterol moieties of the $\mathrm{PMA}_{\mathfrak{c}}$, and, upon addition of $\mathrm{PMA}_{\mathrm{c}}$ capping layer, less liposomal displacement or loss will take place.

For both $\mathrm{L}^{\mathrm{u}, \mathrm{zW}}{ }_{\mathrm{NBD}}$ and $\mathrm{L}^{\mathrm{u},-}{ }_{\mathrm{NBD}}$, decreases in fluorescence intensity of the microreactors were observed after core removal with $\mathrm{HF}\left(\sim 20 \%\right.$ when encapsulating $\mathrm{L}^{\mathrm{u}, \mathrm{Zw}}{ }_{\mathrm{NBD}}$ and $\sim 5 \%$ for $\mathrm{L}^{\mathrm{u},-} \mathrm{NBD}$, independent of the separation layer employed (Figure 1b, i and ii, respectively, white bars)). This finding is consistent with our previous report. ${ }^{[17]}$ Reductions in the fluorescence intensity were also observed when switching the microreactors from $\mathrm{NaOAc}$ buffer (Figure $\mathbf{1 b}$, $\mathbf{i}$ and ii, white bars) to HEPES buffer (Figure 1b, i and ii, bars with stripes), a result that can be explained by the low $\mathrm{pH}-$ dependent fluorescence intensity of the NBD fluorophore ${ }^{[25]}$ and/or by PVP release, which could detach the liposomes, or temporarily increase the permeability of the membrane, thus facilitating the liposomal loss. However, at this stage it is unclear why there are large differences in the decrease in fluorescence as a function of liposome/separation layers employed.

In contrast to the results observed for unsaturated liposomes, when encapsulating both zwitterionic and negatively charged saturated liposomes $\left(\mathrm{L}^{\mathrm{s}, \mathrm{ZW}}{ }_{\mathrm{NBD}}\right.$ and $\left.\mathrm{L}^{\mathrm{s},-}{ }_{\mathrm{NBD}}\right)$ the decrease in fluorescence intensity after the core-shell particle assembly was similar for all four assemblies (Figure 1b, iii and iv, light gray bars), suggesting that the adsorption of saturated liposomes onto the coated silica particles was independent of the separation layer. This effect could be attributed to the ordered gel phase state of the liposomes at room temperature, which promotes more efficient anchoring of the cholesterol moieties. These findings suggest that, when saturated liposomes are 


\section{strandusmall}

employed, the cholesterol-driven anchoring between the $\mathrm{PMA}_{\mathrm{c}}$ capping layer and the liposomes is superior over the electrostatic interactions between $\mathrm{PMA}_{\mathrm{c}}$ and the separation layers.

The stronger binding between cholesterol and saturated liposomes can also be noted by the small drop in fluorescence intensity after core removal in NaOAc buffer (Figure 1b, iii and iv, white bars) and when switching to HEPES buffer (Figure 1b, iii and iv, bars with stripes), suggesting that the stronger cholesterol binding with the saturated liposomes prevents them from being detached upon PVP release.

\subsection{Kinetics of Liposomal Adsorption}

Of the eight previously studied combinations, we chose the optimal separation layer(s) for each type of liposome (unsaturated zwitterionic $\left(\mathrm{L}^{\mathrm{u}, \mathrm{ZW}_{N B D}}\right)$, unsaturated negatively charged $\left(\mathrm{L}^{\mathrm{u},-} \mathrm{NBD}\right)$, saturated zwitterionic $\left(\mathrm{L}^{\mathrm{s}, \mathrm{zw}} \mathrm{NBD}\right)$, and saturated negatively charged $\left.\left(\mathrm{L}^{\mathrm{s},-} \mathrm{NBD}\right)\right)$ which promoted the highest liposomal entrapment at physiological conditions (HEPES buffer): PLL and $\mathrm{L}^{\mathrm{u}, \mathrm{zw}}{ }_{\mathrm{NBD}}$, PLL and $\mathrm{L}^{\mathrm{u},-}{ }_{\mathrm{NBD}}, \mathrm{PLL} / \mathrm{PMA}_{\mathrm{c}}$ and $\mathrm{L}^{\mathrm{s}, \mathrm{ZW}}{ }_{\mathrm{NBD}}$, and PLL/PMA $\mathrm{C}_{\mathrm{c}}$ and $\mathrm{L}^{\mathrm{s},-}{ }_{\mathrm{NBD}}$, to assess the liposomal adsorption kinetics using flow cytometry, and set the fluorescence reading monitored at the saturation point (when the fluorescence intensity reached a plateau) at $100 \%$. As shown in Figure 2, for the different combinations of separation layer/liposome two different trends can be observed. When adsorbing $\mathrm{L}^{\mathrm{u}, 2 \mathrm{w}} \mathrm{NBD}$ onto $\mathrm{SiO}_{2}{ }^{+}-\mathrm{HC}_{300}-\mathrm{PLL}$ particles their fluorescence intensity increased dramatically during the first minute of liposome incubation and reached saturation after less than 20 $\min$ (Figure 2, black squares), while for the other three combinations (PLL/L ${ }^{\mathrm{u},-}{ }_{\mathrm{NBD}}, \mathrm{PLL} / \mathrm{PMA}_{\mathrm{c}} / \mathrm{L}^{\mathrm{s},-}$ NBD, and PLL/PMA $\left./ \mathrm{L}^{\mathrm{s},}{ }_{\mathrm{NBD}}\right)$ saturation occurred in two different steps: $\sim 75 \%$ of the surface of the core-shell particle was covered during the first $20 \mathrm{~min}$, and saturation was reached only after $1 \mathrm{~h}$ (Figure 2, red circles, green triangles, and blue stars). Three of the four different combinations of polymer separation layer/liposome reached the saturation point almost at the same time and 


\section{smallion}

following the same pattern. Thus, since similar adsorption curves were obtained for three of the four separation layer/liposome combinations, we conclude that the adsorption rate of the liposomes is largely independent of the type of the polymer separation layer and the liposomal composition, except when $\mathrm{L}^{\mathrm{u},-} \mathrm{NBD}$ are employed using PLL as a separation layer.

\subsection{Structural Characterization}

The heterogeneous carrier vehicles containing liposomes and polymer capsules as subcompartments were characterized by several microscopy techniques under physiological conditions (Figure 3). Confocal laser scanning microscopy (CLSM) images of the carrier vessels assembled using Alexa Fluor 633 (AF633)-labeled $\mathrm{HC}_{300}\left(\mathrm{HC}_{300(\mathrm{AF} 633)}\right)$, NBD-labeled zwitterionic saturated liposomes $\left(\mathrm{L}^{\mathrm{s}, \mathrm{zw}} \mathrm{NBD}\right)$, and the combination of PLL/PMA $\mathrm{As}_{c}$ as separation layers are shown. Figure 3ai depicts the merged images of the green $\mathrm{L}^{\mathrm{s}, \mathrm{ZW}}{ }_{\mathrm{NBD}}$ and the red $\mathrm{HC}_{300(\mathrm{AF} 633)}$ (giving yellow) and, as it can be observed, while the $\mathrm{L}^{\mathrm{s}, \mathrm{zw}} \mathrm{NBD}$ were homogeneously embedded in the carrier vessel, as shown by the regular yellow or green fluorescence arising from the capsule wall, incorporation of the $\mathrm{HC}_{300(\mathrm{AF} 633)}$ was not as uniform as the liposomes, as shown by the unequally distributed yellow fluorescence arising from the carrier capsule (Figure 3ai). Nonetheless, those results are in agreement with our previous studies in which we encapsulated $\mathrm{HC}_{300}$ within a $3 \mu$ m-diameter carrier capsule. As shown in our previous report, the $\mathrm{HC}_{300}$ were not homogeneously distributed along the polymeric carrier vessel. ${ }^{[8 c]}$ As depicted in Figure 3aii, differential interference contrast (DIC) images show that the subcompartmentalized carriers were intact and non-aggregated, providing evidence for the immobilization of the polymeric subcompartments (Figure 3aii, inset). The negatively stained vessels were also imaged by transmission electron microscopy (TEM), as shown in Figure 3aiii. The images demonstrate the immobilization of the $\mathrm{HC}_{300}$; however, with this technique we are not able to distinguish the liposomes. The comparison of negatively stained 


\section{Submitted to}

microreactors containing only $\mathrm{L}^{\mathrm{s}, \mathrm{zw}}{ }_{\mathrm{NBD}}$ (Figure S1a, Supporting Information) and microreactors containing both $\mathrm{L}^{\mathrm{s}, \mathrm{zw}}{ }_{\mathrm{NBD}}$ and $\mathrm{HC}_{300(\mathrm{AF} 633)}$ as subcompartments (Figure S1b, Supporting Information) visualized by TEM provide additional corroboration for the incorporation of the polymeric subcompartments into the carrier vessel.

Controlling the spatial positioning of the subcompartments is expected to be an advantage for the functional performance of the microreactors. The presented assembly has both types of subunits "membrane-associated", i.e., attached to the polymer membrane of the carrier capsules. In a first step, to gain control over the position of the subcompartments in the heterogeneous vessel, we inverted the assembly order of the liposomes and the $\mathrm{HC}_{300}$. Briefly, we assembled the microreactor by coating $\mathrm{SiO}_{2}{ }^{+}$particles with $\mathrm{PMA}_{c}$, followed by the adsorption of $\mathrm{L}^{\mathrm{s}, \mathrm{zw}}{ }_{\mathrm{NBD}}$, and then depositing $\mathrm{PMA}_{\mathrm{c}}$ and PLL as polymer separation layers. The $\mathrm{HC}_{300(\mathrm{AF} 633)}$ were adsorbed (see Materials and Methods section for details), followed by the sequential deposition of 5 bilayers of PMA $\mathrm{SH}_{\mathrm{SH}}$ and PVP prior to cross-linking and silica core removal. Non-agreggated microreactors containing $\mathrm{L}^{\mathrm{s}, \mathrm{zw}}{ }_{\mathrm{NBD}}$ as the inner subcompartment layer and $\mathrm{HC}_{300(\mathrm{AF} 633)}$ as the outer layer were obtained, as depicted in Figure 3b, which shows the merged CLSM image of $\mathrm{L}^{\mathrm{s}, \mathrm{zw}}{ }_{\mathrm{NBD}}$ (green) and $\mathrm{HC}_{300(\mathrm{AF} 633)}$ (red), giving a yellow color. In a similar manner as when the liposomes were assembled in the microreactor as the outer subcompartment layer and the $\mathrm{HC}_{300(\mathrm{AF} 633)}$ as the inner subcompartment layer (Figure 3ai), when inverting the order of the subcompartments, the $\mathrm{L}^{\mathrm{s}, \mathrm{Zw}}{ }_{\mathrm{NBD}}$ were also homogeneously distributed along the carrier vessel, as shown by the uniformly distributed green or yellow fluorescence (Figure 3b) while the $\mathrm{HC}_{300(\mathrm{AF} 633)}$ were not evenly embedded within the $3 \mu \mathrm{m}$ diameter polymeric container, as shown by the intermittent yellow fluorescence arising from the carrier vessels (Figure 3b).

\subsection{Microreactors with "Free-Floating" Liposomal Subcompartments}




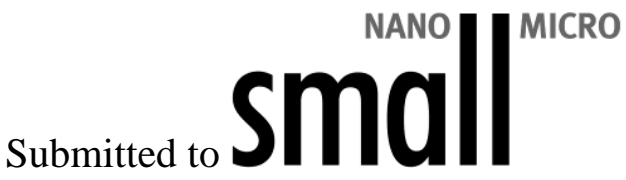

We have previously reported the assembly of capsosomes containing "free-floating" liposomal subcompartments within the interior of the capsules, which was inspired by the arrangement of organelles inside eukaryotic cells. ${ }^{[17]}$ With the goal to obtain a heterogeneous microreactor with control over the spatial positioning of the subunits, i.e., containing the liposomal subcompartments "free-floating" in the vessel's interior, we made use of the properties of $\mathrm{PVP}_{\mathrm{c}}$. This block copolymer consists of a short block of cholesteryl acrylate to bind liposomes and a longer PVP segment ${ }^{[17]}$ which is uncharged and allows hydrogen bonding to other polymer layers. The diblock architecture minimizes physical entanglement of the polymer with the membrane of the carrier capsule promoting the localization of the liposomal compartments into the hollow interior. ${ }^{[17]}$

The assembly was performed by sandwiching $\mathrm{L}^{\mathrm{s}, \mathrm{zw}}{ }_{\mathrm{NBD}}$ between two layers of $\mathrm{PVP}_{\mathrm{c}}$, followed by the deposition of a PMA layer. Three different approaches to attach $\mathrm{HC}_{300(\mathrm{AF} 633)}$ subcompartments were employed (see Materials and Methods for details). The first approach relies on the thioldisulfide exchange. ${ }^{[26]}$ The $\mathrm{SiO}_{2} / \mathrm{PVP}_{\mathrm{c}} / \mathrm{L}^{\mathrm{s}, z \mathrm{~W}}{ }_{\mathrm{NBD}} / \mathrm{PVP}_{\mathrm{c}}$ core-shell particles were first incubated with PMA, subsequently with PVP and then by the adsorption of PMA-pyridine dithioethylamine (PD), followed by the adsorption of the $\mathrm{HC}_{300(\mathrm{AF} 633)}$ in $\mathrm{NaOAc}$ buffer. The second method takes advantage of electrostatic interactions to deposit the $\mathrm{HC}_{300(\mathrm{AF} 633)}$ subunits onto $\mathrm{SiO}_{2} / \mathrm{PVP}_{\mathrm{c}} / \mathrm{L}^{\mathrm{s}, \mathrm{zW}}{ }_{\mathrm{NBD}} / \mathrm{PVP}_{\mathrm{c}} / \mathrm{PMA} / \mathrm{PLL}$ core-shell particles in MES buffer, while the third procedure relies on hydrogen bonding to bind the $\mathrm{HC}_{300(\mathrm{AF} 633)}$ subcompartments onto the $\mathrm{SiO}_{2} / \mathrm{PVP}_{\mathrm{c}} / \mathrm{L}^{\mathrm{s}, \mathrm{zw}}{ }_{\mathrm{NBD}} / \mathrm{PVP}_{\mathrm{c}} / \mathrm{PMA}$ core-shell particles. The coated particles were incubated in a PVP solution and protonated $\mathrm{HC}_{300(\mathrm{AF} 633)}$ were allowed to adsorb overnight. For each of the three methods, the PVP/PMAsH membrane was assembled as described previously. After cross-linking of the thiol groups and core removal, stable microreactors were obtained. Figure 4 shows fluorescence microscopy images of the microreactors assembled by the three different methods in $\mathrm{NaOAc}$ and HEPES buffer. As depicted in Figure 4ai and Figure 4bi, when making use of PMA-PD or PLL to 


\section{smallio}

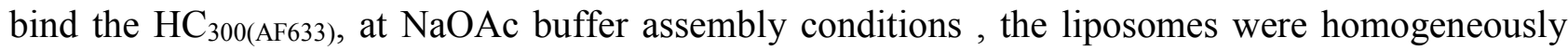
distributed along the carrier vessel while the polymeric subcompartments appear disseminated heterogeneously along the $3 \mu \mathrm{m}$-diameter container. This finding is similar to that previously described for the microreactors containing PLL/PMA $\mathrm{L}^{\mathrm{s}, \mathrm{zW}} \mathrm{NBD}$ as inner and outer subcompartment layers, respectively (Figure 3ai) or vice versa (Figure 3b). However, when employing hydrogen bonding to attach the $\mathrm{HC}_{300(\mathrm{AF} 633) \text {, although the liposomes }}$ appear evenly distributed along the carrier vessel, the hydrogen bond interaction to attach the polymeric subcompartments appears to be ineffective, since the yellow fluorescence arising from the merged fluorescence images of $\mathrm{HC}_{300(\mathrm{AF} 633)}$ (red) and $\mathrm{L}^{\mathrm{s}, \mathrm{ZW}}{ }_{\mathrm{NBD}}$ (green) is irregular and only covers a small part of the carrier vessel.

Following resuspension of the capsules in HEPES buffer, the liposomes were detached from the carrier membrane, as shown by the green fluorescence signal homogeneously distributed within the interior of the carrier vessel while the $\mathrm{HC}_{300(\mathrm{AF} 633)}$ subunits remained associated with the carrier wall (Figure 4aii, Figure 4bii, and Figure 4cii, for the three different methods, respectively).

\subsection{Enzymatic Reactions}

To confirm the incorporation of intact liposomes inside the carrier vehicles, we conducted a colorimetric enzymatic reaction by encapsulating the enzyme $\beta$-lactamase in an assembly consisting of $\mathrm{SiO}_{2}{ }^{+} / \mathrm{HC}_{300} / \mathrm{PMA} / \mathrm{PLL} / \mathrm{PMA}_{\mathrm{c}} / \mathrm{L}^{\mathrm{s}, \mathrm{zw}_{\beta}}{ }_{\text {-lac }} / \mathrm{PMA}_{\mathrm{c}} / \mathrm{PVP} /\left(\mathrm{PMAsH}_{\mathrm{SH}} / \mathrm{PV}\right)_{5}$. The PVP/PMAsh membrane was assembled as described previously but, to prevent enzyme oxidation and thus loss of functionality, the cross-linking of the thiol groups was carried out using thiol-maleimide chemistry by incubating the particles with an excess of the homobifunctional non-degradable linker 1,8 Bismaleimidodiethyleneglycol $\left(\mathrm{BM}(\mathrm{PEG})_{2}\right)$ and core removal was performed by using buffered $\mathrm{HF}$ (2 M HF/8 M ammonium fluoride $\left(\mathrm{NH}_{4} \mathrm{~F}\right)$ ). We previously employed this enzymatic assay, where $\beta$ - 


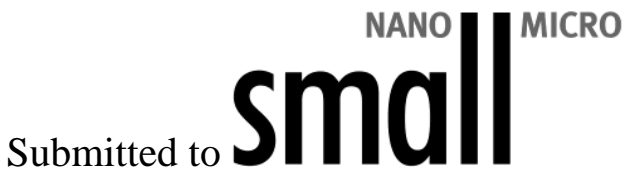

lactamase converts the yellow substrate nitrocefin into its red hydrolyzed product, demonstrating the functionality of capsosomes. ${ }^{[14,15 b]}$ As depicted in Figure 5, the enzymatic reaction only took place when the $\beta$-lactamase-loaded liposomes were lysed using the surfactant Triton X (TX). In the absence of TX no reaction occurred, as evidenced by the pale yellow color after $20 \mathrm{~h}$ of reaction, indicating the presence of non-hydrolyzed nitrocefin (Figure 5, inset b, left tube). On the other hand, when TX was added to the solution, a red-burgundy color was observed, corresponding to the hydrolyzed nitrocefin (Figure 5, inset b, right tube). As expected, there was also a difference in the absorbance readings measured over time in the presence (-) or absence ( $(0)$ of TX (Figure 5), as monitored by UV-vis spectrophotometry. The sample containing TX experienced an increment in the absorbance reading of almost 0.8 units due to an increasing amount of the hydrolyzed nitrocefin product, while the absorbance values of the control sample remained almost constant over time.

\subsection{Degradation of $\mathrm{HC}_{300}$ and Preservation of Liposome Functionality}

With the goal of demonstrating the feasibility of addressing the two types of subunits individually, we attempted to degrade the polymeric subcompartments using a chemical trigger, followed by examining the performance of an enzymatic reaction employing the liposomal subunits. We have previously demonstrated that $\mathrm{HC}_{300}$ cross-linked via oxidation (employing chloramine T), entrapped within a larger non-degradable PMA carrier vessel can be selectively degraded. ${ }^{[8 c]}$ Herein, we sought to demonstrate that the selective degradation of the $\mathrm{HC}_{300}$ subcompartments does not affect the coencapsulated liposomes. To this end, we employed assemblies with different spatial positions of the two types of subunits, i.e., liposomes as the inner subcompartment layer and $\mathrm{HC}_{300}$ as the outer subcompartment layer and vice versa, and exposed them to simulated physiological concentrations $(5 \mathrm{mM})$ of reduced glutathione (GSH). For this assembly, the $\mathrm{HC}_{300}$ were cross-linked with chloramine $\mathrm{T}$ to obtain degradable disulfide bonds, 


\section{smallio}

while the $3 \mu \mathrm{m}$-diameter carrier capsule was cross-linked by making use of the homobifunctional linker $\mathrm{BM}(\mathrm{PEG})_{2}$ to give rise to non-degradable carrier capsules. Interestingly, when assembling a microreactor containing the liposomes as the outer subcompartment layer, the Alexa Fluor 488 (AF488)-labeled $\mathrm{HC}_{300}\left(\mathrm{HC}_{300(\mathrm{AF} 488)}\right)$ were not degraded at simulated physiological concentrations of GSH, as shown by the DIC and fluorescence microscopy images before (Figure 6ai and Figure 6aiii, respectively) and after (Figure 6aii and Figure 6aiv, respectively) incubation with GSH. The images are identical, suggesting that liposomes situated on the outer liposome layer provide an impermeable barrier, thus preventing access of the $\mathrm{GSH}$ peptide into the inner $\mathrm{HC}_{300}$ layer. In contrast, when the liposomes are in the inner subcompartment layer, the $\mathrm{HC}_{300(\mathrm{AF} 488)}$ were completely degraded after $24 \mathrm{~h}$ of incubation with GSH, as shown by the smooth outline of the carrier vessels (Figure 6bii) and the disappearance of the fluorescence signal arising from the labeled $\mathrm{HC}_{300}$ (Figure 6biv).

Further, we also found that the presence of GSH only affects the polymeric subcompartments whereas the liposomes remained intact, as shown by the triggered $\beta$-lactamase assay after $24 \mathrm{~h}$ of incubation with GSH and nitrocefin. As shown in Figure 6c, only when $\beta$-lactamase-loaded liposomes were lysed using the surfactant TX, the yellow substrate nitrocefin (Figure 6ci and Figure 6ciii) was converted into its red hydrolyzed product (Figure 6cii and Figure 6civ). This demonstrates the possibility to selectively address the subunits.

\section{Conclusions}

We have reported the assembly of a micrometer-sized vessel containing subcompartments of two different compositions (liposomes and polymer capsules), and have demonstrated control over the spatial positioning of the subunits. This heterogeneous assembly was employed to conduct a triggered enzymatic reaction, and the possibility to selectively address the polymeric and lipid 


\section{smallio}

subcompartments was shown. These results demonstrate the potential of these heterogeneous compartmentalized carriers in biomedical applications as highly sophisticated microreactors for triggered encapsulated reactions or as drug delivery vehicles.

\section{Experimental Section}

Materials. Poly(L-lysine) (PLL) (40-60 kDa), poly( $N$-vinyl pyrrolidone) (PVP, $10 \mathrm{kDa})$, (4-(2hydroxyethyl)-1-piperazineethanesulfonic acid (HEPES), sodium chloride $(\mathrm{NaCl})$, sodium acetate (NaOAc), $N$-chloro- $p$-toluenesulfonamide sodium salt (chloramine T), reduced L-glutathione (GSH), hydrofluoric acid (HF), dithiothreitol (DTT), ammonium fluoride $\left(\mathrm{NH}_{4} \mathrm{~F}\right)$, Triton $\mathrm{X}-100$ (TX), and $\beta$-lactamase were obtained from Sigma-Aldrich. 3-( $N$-morpholino)propanesulfonic acid (MOPS) was purchased from Acros Organics. 2-( $N$-morpholino)ethanesulfonic acid (MES) was obtained from Merck. 296 nm-diameter $\mathrm{SiO}_{2}$ particles, $3.25 \mu$ m-diameter $\mathrm{SiO}_{2}$ particles and aminemodified $\mathrm{SiO}_{2}$ particles $\left(\mathrm{SiO}_{2}{ }^{+}\right)$were obtained from Microparticles $\mathrm{GmbH}$ (Berlin, Germany). Poly(methacrylic acid) (PMA, $15 \mathrm{kDa})$ was purchased from Polysciences (Pennsylvania, USA). Pyridine dithioethylamine hydrochloride (PDA-HCl) was obtained from Shanghai SpeedChemical Co. Ltd. (Shanghai, China). Alexa Fluor 488 C5 maleimide (AF488) and Alexa Fluor 633 C5 maleimide (AF633) dyes were purchased from Molecular Probes (Invitrogen). Zwitterionic unsaturated lipids 1,2-dioleoyl-sn-glycero-3-phosphocholine (DOPC) (phase transition temperature $\left.\begin{array}{ll}-20 & { }^{\circ} \mathrm{C}\end{array}\right)$, negatively charged unsaturated lipids 1,2-dioleoyl-sn-glycero-3-(phospho-L-serine) (DOPS) (phase transition temperature $-11{ }^{\circ} \mathrm{C}$ ), zwitterionic saturated lipids 1,2-dimyristoyl-snglycero-3-phosphocholine (DMPC) (phase transition temperature $23{ }^{\circ} \mathrm{C}$ ), 1,2-dipalmitoyl-snglycero-3-phosphocholine (DPPC) (phase transition temperature $41{ }^{\circ} \mathrm{C}$ ), negatively charged saturated lipids 1,2-dipalmitoyl-sn-glycero-3-(phospho-L-serine) (DPPS) (phase transition temperature $54{ }^{\circ} \mathrm{C}$ ), and fluorescent lipids 1-myristoyl-2-[12-[(7-nitro-2-1,3-benzoxadiazol-4- 


\section{smallio}

yl)amino]-hexanoyl]-sn-glycero-3-phosphocholine (NBD-PC), were purchased from Avanti Polar Lipids (Alabama, USA). 1,8-Bismaleimidodiethyleneglycol $\mathrm{BM}(\mathrm{PEG})_{2}$ was obtained from Thermo Fisher (Massachusetts, USA). Nitrocefin was purchased from Oxoid (Thermo Fischer Scientific) (Massachusetts, USA), and chloroform was obtained from Chem Supply.

Four different types of buffers were used throughout all of the experiments: HEPES buffer, consisting of $10 \mathrm{mM}$ HEPES and $150 \mathrm{mM} \mathrm{NaCl}(\mathrm{pH} 7.4)$; NaOAc buffer, consisting of $20 \mathrm{mM}$ NaOAc (pH 4.0); MES buffer consisting of 100 mM MES ( $\mathrm{pH} 5.0$ ); and MES buffer consisting of $50 \mathrm{mM}$ MES (pH 6.0). The buffer solutions were made with ultrapure water (Milli-Q gradient A 10 system, resistance $18 \mathrm{M} \Omega \mathrm{cm}, \mathrm{TOC}<4 \mathrm{ppb}$, Millipore Corporation, USA).

Methods. Liposomes: Unilamellar liposomes were prepared by the evaporation of chloroform (2.5 $\mathrm{mg}$ lipids dissolved in chloroform) under nitrogen for $1 \mathrm{~h}$ followed by hydration using $1 \mathrm{~mL}$ $\mathrm{NaOAc}$ buffer, and extrusion through $50 \mathrm{~nm}$ filters $(31 \times)$. For fluorescently labeled liposomes, $1 \%$ (w/w) of NBD-PC dissolved in chloroform was added to the lipid solution prior to drying. For enzyme-loaded liposomes the hydration was performed with $200 \mu \mathrm{L}$ of $\beta$-lactamase $\left(3 \mathrm{mg} \mathrm{mL}^{-1}\right)$ in HEPES buffer and then diluted to a total volume of $1 \mathrm{~mL}$ with HEPES buffer.

Zwitterionic unsaturated liposomes $\left(\mathrm{L}^{\mathrm{u}, \mathrm{zw}}{ }_{\mathrm{NBD}}\right)$ consisted of DOPC, $\mathrm{L}^{\mathrm{u}, \mathrm{zw}}$; negatively charged unsaturated liposomes $\left(\mathrm{L}^{\mathrm{u},-} \mathrm{NBD}\right)$ consisted of DOPC:DOPS=4:1 wt/wt, $\mathrm{L}^{\mathrm{u},-}$; zwitterionic saturated liposomes $\left(\mathrm{L}^{\mathrm{s}, \mathrm{zw}}{ }_{\mathrm{NBD}}\right)$ consisted of DMPC:DPPC=4:1 wt/wt, $\mathrm{L}^{\mathrm{s}, \mathrm{zw}}$; negatively charged saturated liposomes $\left(\mathrm{L}^{\mathrm{s},-} \mathrm{NBD}\right)$ consisted of DMPC:DPPC:DPPS=5:1:2 wt/wt, $\mathrm{L}^{\mathrm{s},-}$; and as fluorescent lipids, 1 wt $\%$ NBD-PC was employed.

Polymer Synthesis: Thiol-modified poly(methacrylic acid) (PMAsH, $15 \mathrm{kDa}),{ }^{[26]}$ which in this study consists of a PMA backbone with $14 \%$ pendant thiol moieties, poly-(methacrylic acid)-co(cholesteryl methacrylate) $\left(\mathrm{PMA}_{\mathrm{c}}, 12.4 \mathrm{kDa}\right),{ }^{[16]}$ and poly(N-vinyl pyrrolidone)-block-(cholesteryl acrylate) $\left(\mathrm{PVP}_{\mathrm{c}}, 10.9 \mathrm{kDa}\right)^{[17]}$ were synthesized according to previously published protocols. 


\section{smallio}

Assembly of $300 \mathrm{~nm}$-diameter PMA Capsules $\left(\mathrm{HC}_{300}\right)$ : The preparation and the labeling of the $\mathrm{HC}_{300}$ is described elsewhere. ${ }^{[8 c]}$

Microreactor Assembly: Microreactors were assembled via the layer-by-layer (LbL) technique.

(a) Microreactors containing $H C_{300}$ as the inner subcompartment layer and liposomes as the outer subcompartment layer: $\mathrm{HC}_{300}$ were adsorbed onto $3 \mu \mathrm{m}$-diameter $\mathrm{SiO}_{2}{ }^{+}$particles in $\mathrm{MES}$ buffer (100 mM, pH 5.0) for 5 min with constant shaking followed by the addition of PMA to a final concentration of $1 \mathrm{mg} \mathrm{mL}^{-1}$ for $10 \mathrm{~min}$ with constant shaking. The sample was washed three times in HEPES buffer $(1060 \mathrm{~g}, 30 \mathrm{~s})$ and then incubated in a PLL solution ( $\left.1 \mathrm{mg} \mathrm{mL}^{-1}, 10 \mathrm{~min}\right)$, washed three times in HEPES buffer, followed by the adsorption of a PMA solution if desired $\left(1 \mathrm{mg} \mathrm{mL} \mathrm{PL}^{-1}\right.$, 15 min), washed three times in HEPES, suspended in a liposome solution at $37{ }^{\circ} \mathrm{C}$ when adsorbing saturated liposomes $\left(1.25 \mathrm{mg} \mathrm{mL}^{-1}, 40 \mathrm{~min}\right)$, washed three times in HEPES, incubated in a PMA solution again ( $\left.1 \mathrm{mg} \mathrm{mL}^{-1}, 15 \mathrm{~min}\right)$, washed twice in HEPES, followed by assembly of the polymer membrane of the carrier capsules by the sequential deposition of five bilayers of PVP and PMAsH $\left(1 \mathrm{mg} \mathrm{mL} \mathrm{m}^{-1}, 10 \mathrm{~min}\right)$ in NaOAc buffer $(\mathrm{pH} 4.0)$. The thiols within the polymer layers were crosslinked using chloramine $\mathrm{T}(2.5 \mathrm{mM}$ in MES buffer $(50 \mathrm{mM}, \mathrm{pH} 6.0), 1 \mathrm{~min})$ or by using thiolmaleimide chemistry by incubating the particles overnight in an excess volume of $0.3 \mathrm{~g} \mathrm{~L}^{-1}$ of $\mathrm{BM}(\mathrm{PEG})_{2}$ solution in MES buffer (50 mM, pH 6.0). By converting the thiol groups into covalent linkages, the multilayers remain intact when exposed to alkaline or neutral solutions. Above the $\mathrm{p} K_{\mathrm{a}}$ of PMA ( $\mathrm{pH}$ 6.5) the hydrogen bonds are disrupted, thus releasing the PVP, and resulting in singlecomponent, cross-linked PMA HCs.

The silica cores were dissolved using a 5 M HF solution for 2 min (Caution: hydrofluoric acid is extremely corrosive and should be handled with care), followed by several washing cycles in NaOAc buffer $(4500 \mathrm{~g}, 3 \mathrm{~min})$. When the microreactor was assembled with $\beta$-lactamase-loaded 


\section{smallio}

liposomes the core was removed using a 2:1 $\mathrm{v} / \mathrm{v} 2 \mathrm{M} \mathrm{HF} / 8 \mathrm{M} \mathrm{NH}_{4} \mathrm{~F}$ solution for $2 \mathrm{~min}$, followed by several washing cycles in $\mathrm{NaOAc}$ buffer $(4500 \mathrm{~g}, 3 \mathrm{~min})$.

The microreactors were post-labeled with a fluorescent dye when required by incubation in a solution of AF488 or AF633 $\left(5 \times 10^{-3} \mathrm{mg} \mathrm{mL}^{-1}\right.$ in MES buffer $\left.(50 \mathrm{mM}, \mathrm{pH} 6.0,1 \mathrm{~h})\right)$. The microreactors were then washed three times in HEPES buffer (1060 $g, 30 \mathrm{~s})$.

(b) Microreactors containing liposomes as the inner subcompartment layer and $\mathrm{HC}_{300}$ as the outer subcompartment layer. $3 \mu \mathrm{m}$-diameter $\mathrm{SiO}_{2}{ }^{+}$particles $(5 \mathrm{wt} \%)$ were washed three times in HEPES buffer $(1060 \mathrm{~g}, 30 \mathrm{~s})$. The particles were then suspended in a PMA $\mathrm{c}$ solution $\left(1 \mathrm{mg} \mathrm{mL}^{-1}, 15\right.$ min), washed three times in HEPES, followed by the adsorption of the liposomes $\left(1.25 \mathrm{mg} \mathrm{mL}^{-1}, 40\right.$ min), washed three times in HEPES, and subsequently the PMAc capping layer was adsorbed (1 mg $\left.\mathrm{mL}^{-1}, 15 \mathrm{~min}\right)$, washed three times in HEPES and incubated with a PLL solution $\left(1 \mathrm{mg} \mathrm{mL}^{-1}, 10\right.$ min), washed three times in HEPES, followed by the adsorption of $\mathrm{HC}_{300}$ in HEPES buffer for 5 min with constant shaking. PMA was added to a final concentration of $1 \mathrm{mg} \mathrm{mL}^{-1}$ and incubated for 10 min with constant shaking. The sample was then washed twice in HEPES buffer and once in NaOAc buffer $(1060 \mathrm{~g}, 30 \mathrm{~s})$. The polymer membrane was assembled by the sequential deposition of five bilayers of PVP and PMAsH $\left(1 \mathrm{mg} \mathrm{mL}^{-1}, 10 \mathrm{~min}\right)$ in NaOAc $(\mathrm{pH} 4.0)$. The thiols within the polymer layers were cross-linked and the silica core was dissolved as described previously. The PVP was released from the microreactors by washing them into HEPES buffer.

Microreactors containing "free-floating" liposomal subcompartments and "membraneassociated" $\mathrm{HC}_{300 .} 3 \mu \mathrm{m}$-diameter $\mathrm{SiO}_{2}$ particles $(5 \mathrm{wt} \%)$ were washed three times in $\mathrm{NaOAc}$ buffer $(1060 \mathrm{~g}, 30 \mathrm{~s})$, the particles were incubated in a $\mathrm{PVP}_{\mathrm{c}}$ solution $\left(1 \mathrm{mg} \mathrm{mL}^{-1}, 15 \mathrm{~min}\right)$, washed three times in $\mathrm{NaOAc}$, incubated in a liposomal solution $\left(\mathrm{L}^{\mathrm{s}, \mathrm{zw}} \mathrm{NBD}\right)$ at $37^{\circ} \mathrm{C}\left(1.25 \mathrm{mg} \mathrm{mL}^{-1}, 40 \mathrm{~min}\right)$, washed three times in $\mathrm{NaOAc}$, followed again by the adsorption of a $\mathrm{PVP}_{\mathrm{c}}$ solution $\left(1 \mathrm{mg} \mathrm{mL}^{-1}, 15\right.$ 


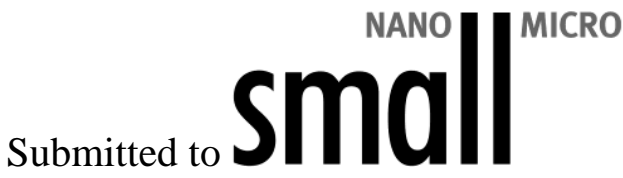

min) and washing three times in $\mathrm{NaOAc}$. After these steps, three different assembly methods were employed:

(a) The coated particles were incubated with a PMA solution $\left(1 \mathrm{mg} \mathrm{mL}^{-1}, 10 \mathrm{~min}\right)$, washed three times in NaOAc buffer, suspended in a PVP solution $\left(1 \mathrm{mg} \mathrm{mL}^{-1}, 10 \mathrm{~min}\right)$, and washed three times in NaOAc. Subsequently they were allowed to interact with a PMA-PD solution $\left(1 \mathrm{mg} \mathrm{mL}{ }^{-1}\right.$, overnight), washed three times in $\mathrm{NaOAc}$, followed by the adsorption of $\mathrm{HC}_{300}$ in $\mathrm{NaOAc}$ buffer for 5 min with constant shaking. PMA was added to a final concentration of $1 \mathrm{mg} \mathrm{mL}^{-1}$ and incubated for 10 min with constant shaking. The sample was then washed three times in $\mathrm{NaOAc}$ and the polymer membrane was assembled as described previously followed by the thiol cross-linking and the core dissolution.

(b) The coated particles were incubated with a PMA solution $\left(1 \mathrm{mg} \mathrm{mL}^{-1}, 10 \mathrm{~min}\right)$, washed three times in MES buffer (100 mM, pH 5.0), and then incubated with a PLL solution (1 mg mL ${ }^{-1}, 10$ min), washed three times in MES buffer (100 mM, $\mathrm{pH}$ 5.0), and subsequently $\mathrm{HC}_{300}$ suspended in MES buffer (100 mM, pH 5.0) were added dropwise and incubated for 5 min with constant shaking, followed by the addition of PMA to a final concentration of $1 \mathrm{mg} \mathrm{mL}^{-1}$. The coated particles were then washed once in MES (100 mM, pH 5.0) buffer and 2 times in NaOAc buffer. The assembly of the polymer membrane, the thiol cross-linking, and the core dissolution were then performed as described previously.

(c) The coated particles were incubated with a PMA solution $\left(1 \mathrm{mg} \mathrm{mL}^{-1}, 10 \mathrm{~min}\right)$, washed three times in NaOAc buffer, and then incubated with PVP $\left(1 \mathrm{mg} \mathrm{mL}^{-1}, 10 \mathrm{~min}\right)$ washed three times in $\mathrm{NaOAc}$, and $\mathrm{HC}_{300}$ in $\mathrm{NaOAc}$ buffer were added dropwise and then incubated overnight with constant shaking. The subsequent assembly of the polymer membrane, thiol cross-linking, and core dissolution were then performed as described previously. 


\section{smallion}

Flow Cytometry: A CyFlow Space (PartecFlowmax, Münster, Germany) flow cytometer using an excitation wavelength of $488 \mathrm{~nm}$ or $633 \mathrm{~nm}$ was used for all of the flow cytometry experiments. At least 20000 particles were analyzed in each experiment.

Transmission Electron Microscopy: A FEI Tecnai TF30 instrument (FEI-Company, Eindhoven, The Netherlands) operating at $200 \mathrm{kV}$ and fitted with a Gatan US1000 $2000 \times 2000 \mathrm{CCD}$ camera (Pleasenton, Ca, USA) was used for TEM imaging. TEM grids were plasma treated for $10 \mathrm{~s}$ before use. The sample $(5 \mu \mathrm{L})$ was adsorbed onto a carbon-coated Formvar film mounted on 200-mesh copper grids (ProSciTech, Australia) for $5 \mathrm{~min}$. The grids were blotted and dipped into a 1.5\% aqueous uranyl acetate solution for $15 \mathrm{~s}$ for negative staining.

Optical Microscopy: DIC and fluorescence images were taken on an inverted Olympus IX71 digital wide-field microscope equipped with a DIC slider (U-DICT, Olympus) using the corresponding filter sets and a $60 \times$ oil immersion objective (Olympus UPFL20/0.5NA, W.D.1.6). Confocal laser scanning microscopy (CLSM) images were acquired using a Leica TCS SP2 AOBS (Leica, Germany) microscope equipped with an Ar laser $(\lambda=488 \mathrm{~nm})$, a HeNe laser $(\lambda=633 \mathrm{~nm})$ and a $63 \times$ oil immersion objective.

Enzymatic Hydrolysis of Nitrocefin by $\beta$-Lactamase: A suspension of $8.3 \times 10^{7}$ microreactors in $50 \mu \mathrm{L}$ of PBS buffer solution at $\mathrm{pH} 7.0$ containing nitrocefin $(50 \mu \mathrm{g} \mathrm{mL}-1)$ was incubated with $\mathrm{TX}$ at a final concentration of $0.5 \% \mathrm{v} / \mathrm{v}$. The conversion of the nitrocefin substrate into its hydrolyzed product was monitored over time by absorbance measurements at $492 \mathrm{~nm}$ using a NanoDrop 1000 spectrophotometer (Thermo Fischer Scientific).

\section{Acknowledgements}

This work was supported by the Australian Research Council under the Australian Laureate Fellowship (F.C.) and Discovery Project (F.C.) schemes. We thank Dr. Almar Postma (CSIRO 


\section{tratano sostinestis Small}

Molecular and Health Technologies) for the synthesis of $\mathrm{PMA}_{\mathrm{c}}$ and $\mathrm{PVP}_{\mathrm{c}}$, Christopher J. Ochs (The

University of Melbourne) for his assistance with the TEM images, and Rona Chandrawati (The University of Melbourne) for her advice with the $\beta$-lactamase reaction.

\section{REFERENCES}

[1] a) M. Marguet, C. Bonduelle, S. Lecommandoux, Chem. Soc. Rev. 2013, 42, 512; b) M. Marguet, L. Edembe, S. Lecommandoux, Angew. Chem. Int. Ed. 2012, $51,1173$.

[2] A. M. Brizard, J. H. Van Esch, Soft Matter 2009, 5, 1320.

[3] Y. Zhang, W. C. Ruder, P. R. LeDuc, Trends Biotechnol. 2008, 26, 14.

[4] B. Städler, A. D. Price, R. Chandrawati, L. Hosta-Rigau, A. N. Zelikin, F. Caruso, Nanoscale 2009, 1, 68.

[5] R. Chandrawati, F. Caruso, Langmuir 2012, 28, 13798.

[6] a) E. T. Kisak, B. Coldren, C. A. Evans, C. Boyer, J. A. Zasadzinski, Curr. Med. Chem. 2004, 11, 199; b) V. Mishra, S. Mahor, A. Rawat, P. Dubey, P. N. Gupta, P. Singh, S. P. Vyas, Vaccine 2006, 24, 5559.

[7] A. F. Thunemann, S. Kubowicz, H. von Berlepsch, H. Mohwald, Langmuir 2006, 22, 2506.

[8] a) K. J. Pekarek, J. S. Jacob, E. Mathiowitz, Nature 1994, 367, 258; b) B. G. De Geest, S. De Koker, K. Immesoete, J. Demeester, S. C. De Smedt, W. E. Hennink, Adv. Mater. 2008, 20, 3687; c) O. Kulygin, A. D. Price, S. F. Chong, B. Stadler, A. N. Zelikin, F. Caruso, Small 2010, 6, 1558 .

[9] a) H. C. Chiu, Y. W. Lin, Y. F. Huang, C. K. Chuang, C. S. Chern, Angew. Chem. Int. Ed. 2008, 47, 1875; b) Z. Fu, M. A. Ochsner, H.-P. M. de Hoog, N. Tomczak, M. Nallani, Chem. Commun. 2011, 47, 2862; c) H. C. Shum, Y.-j. Zhao, S.-H. Kim, D. A. Weitz, Angew. Chem. Int. Ed. 2011, 50, 1648; d) M. Marguet, O. Sandre, S. Lecommandoux, Langmuir 2012, 28, 2035.

[10] C. D. Driever, X. Mulet, A. P. R. Johnston, L. J. Waddington, H. Thissen, F. Caruso, C. J. Drummond, Soft Matter 2011, 7, 4257.

[11] H. Lomas, A. P. R. Johnston, G. K. Such, Z. Zhu, K. Liang, M. P. Van Koeverden, S. Alongkornchotikul, F. Caruso, Small 2011, 7, 2109.

[12] R. F. Fakhrullin, V. N. Paunov, Chem. Commun. 2009, 2511.

[13] H. Baumler, R. Georgieva, Biomacromolecules 2010, 11, 1480.

[14] B. Städler, R. Chandrawati, A. D. Price, S.-F. Chong, K. Breheney, A. Postma, L. A. Connal, A. N. Zelikin, F. Caruso, Angew. Chem. Int. Ed. 2009, 48, 4359.

[15] a) B. Städler, R. Chandrawati, K. Goldie, F. Caruso, Langmuir 2009, 25, 6725; b) R. Chandrawati, L. Hosta-Rigau, D. Vanderstraaten, S. A. Lokuliyana, B. Städler, F. Albericio, F. Caruso, ACS Nano 2010, 4, 1351.

[16] R. Chandrawati, B. Städler, A. Postma, L. A. Connal, S.-F. Chong, A. N. Zelikin, F. Caruso, Biomaterials 2009, 30, 5988.

[17] L. Hosta-Rigau, S. F. Chung, A. Postma, R. Chandrawati, B. Städler, F. Caruso, Adv. Mater. 2011, 23, 4082.

[18] R. Chandrawati, P. D. Odermatt, S. F. Chong, A. D. Price, B. Städler, F. Caruso, Nano Lett. 2011, 11, 4958. 
[19] a) L. Hosta-Rigau, B. Städler, Y. Yan, E. C. Nice, J. K. Heath, F. Albericio, F. Caruso, Adv. Funct. Mater. 2010, 20, 59; b) L. Hosta-Rigau, R. Chandrawati, E. Saveriades, P. D. Odermatt, A. Postma, F. Ercole, K. Breheney, K. L. Wark, B. Städler, F. Caruso, Biomacromolecules 2010, 11, 3548.

[20] A. D. Price, A. N. Zelikin, Y. J. Wang, F. Caruso, Angew. Chem. Int. Ed. 2009, 48, 329.

[21] A. D. Price, A. N. Zelikin, K. L. Wark, F. Caruso, Adv. Mater. 2010, 22, 720.

[22] H.-P. M. de Hoog, M. Nallani, N. Tomczak, Soft Matter 2012, 8, 4552.

[23] A. N. Zelikin, J. F. Quinn, F. Caruso, Biomacromolecules 2006, 7, 27.

[24] R. Chandrawati, S. F. Chong, A. N. Zelikin, L. Hosta-Rigau, B. Städler, F. Caruso, Soft Matter 2011, 7, 9638.

[25] K. Ishiguro, T. Ando, O. Watanabe, H. Goto, BMC Gastroenterol. 2010, 10.

[26] a) S.-F. Chong, R. Chandrawati, B. Städler, J. Park, J. H. Cho, Y. J. Wang, Z. F. Jia, V. Bulmus, T. P. Davis, A. N. Zelikin, F. Caruso, Small 2009, 5, 2601; b) K. R. West, K. D. Bake, S. Otto, Org. Lett. 2005, 7, 2615.

Received: ((will be filled in by the editorial staff))

Revised: ((will be filled in by the editorial staff)) Published online on ((will be filled in by the editorial staff)) 


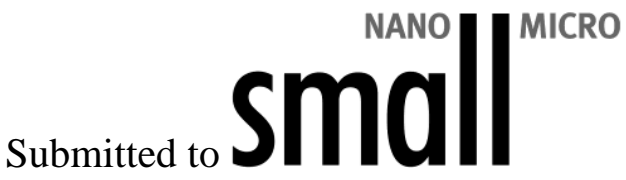

Scheme 1. Schematic representation of a microreactor containing subcompartments of different composition: (i) $300 \mathrm{~nm}$-diameter polymer hydrogel capsules $\left(\mathrm{HC}_{300}\right)$ that can be degraded at physiological concentrations of glutathione (GSH), which are able to convert disulfide bonds (a) into thiol groups (b), thus degrading the capsules; and (ii) 50 nm-diameter $\beta$-lactamase loaded liposomes, which are able to convert the yellow substrate nitrocefin into its red hydrolyzed product.

Figure 1. a) Schematic representation of the microreactor assembly. $\mathrm{HC}_{300}$ were adsorbed onto silica particles and, next, two polymer separation layers (poly(L-lysine) (PLL) and/or poly(methacrylic acid)-co-(cholesteryl methacrylate) ( $\mathrm{PMA}_{c}$ ) were deposited, followed by liposome adsorption. The coated silica particles were capped with $\mathrm{PMA}_{\mathrm{c}}$ and the polymer carrier capsule was created by the sequential deposition of five bilayers of poly( $N$-vinyl pyrrolidone) (PVP) and thiolated poly(methacrylic acid) $\left(\mathrm{PMA}_{\mathrm{SH}}\right)$ in $\mathrm{NaOAc}$ buffer. The thiols in the polymer multilayer film were then crosslinked followed by core dissolution. The microreactors were then washed in HEPES buffer. b) Liposome retention depending on the polymer separation layers deposited onto $\mathrm{SiO}_{2}{ }^{+}-\mathrm{HC}_{300}$ core-shell particles. The fluorescence intensity of core-shell particles or hollow microreactors due to the presence of NBD-labeled liposomes $\left(\mathrm{L}_{\mathrm{NBD}}\right)$ at different stages of the assembly is shown: after the initial liposome deposition (dark gray), after the assembly of the coreshell particles (gray), hollow microreactors in NaOAc buffer (white), and in HEPES buffer (stripes), for liposomes with different lipid compositions: i) unsaturated zwitterionic $\left(\mathrm{L}^{\mathrm{u}, \mathrm{zw}}{ }_{\mathrm{NBD}}\right)$; ii) unsaturated negatively charged ( $\left(\mathrm{L}^{\mathrm{u},-}{ }_{\mathrm{NBD}}\right)$; iii) saturated zwitterionic $\left(\mathrm{L}^{\mathrm{s}, \mathrm{zw}}{ }_{\mathrm{NBD}}\right)$; and (iv) saturated negatively charged $\left(\mathrm{L}^{\mathrm{S},-} \mathrm{NBD}\right)$. The red arrows indicate the reduction in the fluorescence intensity of the adsorbed liposomes (or liposome loading efficiency) before dissolution of the microreactor core. 
Figure 2. Adsorption kinetics of NBD-labeled liposomes onto $\mathrm{SiO}_{2}{ }^{+}-\mathrm{HC}_{300} /$ separation layer coreshell particles using the polymer separation layers that enable the highest liposomal encapsulation for the four different liposomal compositions: $\mathrm{L}^{\mathrm{u}, \mathrm{zw}} \mathrm{NBD}$, PLL separation layer (black squares); $\mathrm{L}^{\mathrm{u},-}$ NBD, PLL separation layer (red circles); $\mathrm{L}_{\mathrm{NBD}}^{\mathrm{s}, \mathrm{zw}}$, PLL/PMA $\mathrm{c}_{\mathrm{c}}$ separation layer (green triangles); and $\mathrm{L}^{\mathrm{S},-}$ NBD, PLL/PMAc separation layer (blue stars). 
Figure 3. Structural integrity of heterogeneous microreactors in HEPES buffer: a) merged CLSM image of microreactors containing NBD-labeled liposomes $\left(\mathrm{L}^{\mathrm{s}, \mathrm{Zw}}{ }_{\mathrm{NBD}}\right)$, AF633-labeled $\mathrm{HC}_{300}$ $\left(\mathrm{HC}_{300(\mathrm{AF} 633)}\right)$ using a combination of PLL/PMA $\mathrm{c}_{\mathrm{c}}$ as the separation layers (i) and DIC (ii) and TEM (iii) images of the same microreactors; b) merged CLSM image of microreactors containing NBDlabeled liposomes $\left(\mathrm{L}^{\mathrm{s}, \mathrm{Zw}} \mathrm{NBD}\right)$ as the inner subcompartment layer and $\mathrm{HC}_{300(\mathrm{AF} 633)}$ as the outer subcompartment layer. 
Figure 4. Merged CLSM images of carrier vessels containing AF633 $\mathrm{HC}_{300}\left(\mathrm{HC}_{300(\mathrm{AF} 633)}\right)$ associated with the carrier membrane and "free-floating" NBD-labeled liposomal subcompartments $\left(\mathrm{L}^{\mathrm{s}, \mathrm{ZW}}{ }_{\mathrm{NBD}}\right)$ in the carrier cavity for three different assemblies: a) $\left(\mathrm{PVP}_{\mathrm{c}} / \mathrm{L}^{\mathrm{s}, \mathrm{Zw}}{ }_{\mathrm{NBD}} / \mathrm{PVP} / \mathrm{PMA} / \mathrm{PVP} / \mathrm{PMA}-\mathrm{PD} / \mathrm{HC}_{300(\mathrm{AF} 633)} / \mathrm{PVP} /\left(\mathrm{PMA}_{\mathrm{SH}} / \mathrm{PVP}\right)_{5}\right)$; $\left(\mathrm{PVP}_{\mathrm{c}} / \mathrm{L}^{\mathrm{s}, \mathrm{Zw}}{ }_{\mathrm{NBD}} / \mathrm{PVP} / \mathrm{PMA} / \mathrm{PLL} / \mathrm{HC}_{300(\mathrm{AF} 633) / \mathrm{PVP} /}\right.$ $\left.\left(\mathrm{PMA}_{\mathrm{SH}} / \mathrm{PVP}\right)_{5}\right)$; and c) $\left(\mathrm{PVP}_{\mathrm{c}} / \mathrm{L}^{\mathrm{s}, \mathrm{Zw}}{ }_{\mathrm{NBD}} / \mathrm{PVP} / \mathrm{PMA} / \mathrm{PVP} / \mathrm{HC}_{300(\mathrm{AF} 633)} / \mathrm{PVP} /\left(\mathrm{PMA}_{\mathrm{SH}} / \mathrm{PVP}\right)_{5}\right)$ in assembly conditions of (NaOAc buffer) (i) and in HEPES buffer (ii). 
Figure 5. Enzymatic conversion rates of $\beta$-lactamase-loaded liposomes embedded into a heterogeneous microreactor. Photographs taken at a) the start of the reaction and b) after $20 \mathrm{~h}$ for microreactors containing $\beta$-lactamase-loaded liposomes with or without the addition of Triton $\mathrm{X}$ (TX). The absorbance readings over time of the $\beta$-lactamase assay using heterogeneous microreactors in the presence $(\mathbf{})$ or absence ( $(0)$ of TX are also shown. 
Figure 6. Degradation of the $\mathrm{HC}_{300}$ by reduced glutathione (GSH). a) Carrier vessel containing the $\mathrm{HC}_{300}$ as the inner subcompartment layer and the liposomes as the outer subcompartment layer. DIC images before (i) and after (ii) incubation with GSH. Fluorescence microscopy images of AF488labeled $\mathrm{HC}_{300}\left(\mathrm{HC}_{300(\mathrm{AF} 488)}\right)$ before (iii) and after (iv) incubation with GSH. b) Carrier vessel containing liposomes as the inner subcompartment layer and $\mathrm{HC}_{300(\mathrm{AF} 488)}$ as the outer subcompartment layer. DIC images before (i) and after (ii) incubation with GSH. Fluorescence microscopy images of $\mathrm{HC}_{300(\mathrm{AF} 488)}$ before (iii) and after (iv) incubation with GSH. c) Schematic illustration of the enzymatic reaction of microreactors containing $\beta$-lactamase-loaded liposomes after degradation of the $\mathrm{HC}_{300(\mathrm{AF} 488)}$ compartments. Reaction tubes before (i and iii) and after (ii and iv) the addition of Triton X (TX). 
sunisus smallio

\section{Table of Contents}

We report the assembly of a polymer capsule microreactor containing subcompartments of different composition, polymeric capsules and liposomes. We demonstrate control over the position of the subcompartments, selective degradation of the polymeric subunits, and preservation of cargo functionality within the liposomal subunits through enzymatic reactions.

TOC Keyword

L. Hosta-Rigau, O. Shimoni, B. Städler, F. Caruso*((same order as byline))

Advanced Subcompartmentalized Microreactors: Polymer Hydrogel Carriers Encapsulating Polymer Capsules and Liposomes

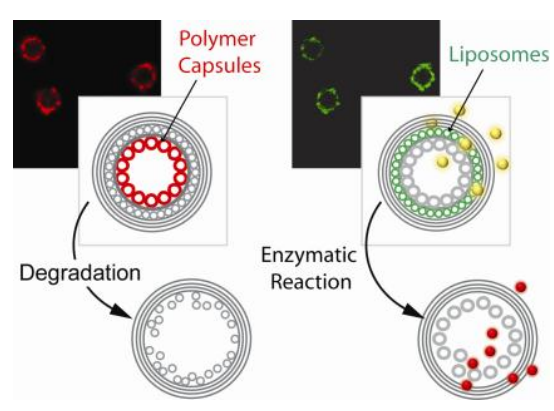

Page Headings

Left page: L. Hosta-Rigau et al.

Right page: Advanced Microreactors 